S sciendo

\title{
Epistemology Neutralized
}

\author{
Brian Laetz \\ University of British Columbia
}

Disputatio Vol. 3, No. 28

May 2010

DOI: $10.2478 /$ disp-2010-0001

ISSN: 0873-626X 


\title{
Epistemology neutralized
}

\author{
Brian Laetz \\ University of British Columbia
}

\begin{abstract}
The thesis that knowledge is a partly evaluative concept is now a widespread view in epistemology, informing some prominent debates in the field. Typically, the view is embraced on the grounds that justification is a necessary condition for knowledge and a normative concept — a reasonable motivation. However, the view also has counterintuitive implications, which have been neglected. In particular, it implies that J.L. Mackie's error-theory of value entails global epistemic scepticism and that any true knowledge claim suffices to prove the error-theory is false. In this paper, I elaborate these difficulties and address objections at length.
\end{abstract}

\section{Keywords}

Definition of knowledge, epistemic justification, epistemic scepticism, error-theory of value, J.L. Mackie.

\section{Introduction}

The thesis that knowledge is a partly evaluative concept, which I will call epistemic evaluativism, is a widespread view in contemporary epistemology. Typically, it is embraced on the grounds that justification is both a necessary condition for knowledge and a normative concept. However, various epistemologists, divided on a number of issues, are united in their commitment to this view. To get a feel for the range and diversity of epistemic evaluativists, consider some notable proponents.

A classic instance is provided by A.J. Ayer, who famously suggested that knowledge not only requires true belief, but also the 'right to be sure' that one's belief is true (1956: 28-34). More recently, virtue epistemologists have also embraced the view, such as Linda Zagzebski, who not only claims that knowledge is a normative concept, but has variously defined knowledge as good true belief or belief arising out of acts of intellectual virtue (1999). Deontic theorists of justifica-

Disputatio, Vol. III, No. 28, May 2010

Received on 26 September 2009 
tion provide another example, like Matthias Steup, who takes 'the concept of epistemic justification to be a deontological one,' belonging 'to the family of deontological concepts, concepts such as permission, prohibition, obligation, blame, and responsibility' (1998: 311). The thesis also cuts across key divides in the field. Here, the sentiments of internalists are even echoed by externalist Alvin Goldman, who avers that 'justification and rationality are normative concepts' and that 'knowledge is another partly normative concept of philosophical epistemology' (2006: 10). The position is even routinely embraced in textbooks, where the thesis that justification is normative has become something of a truism (e.g., Moser 1998: 36-38; Pollock 1999: 11; Steup 1996: 69). Epistemic evaluativism is not just a popular thesis though; it also contributes to some important debates, most notably, the controversy regarding naturalized epistemology and the internalism-externalism dispute.

On one familiar line of criticism, due to Jaegwon Kim (1988), Quinean naturalized epistemology (1969) fails to be a reasonable successor to traditional epistemology, precisely because Quine's program is descriptive, and thus neglects the normative concept of justification. But Kim objects, 'if justification drops out of epistemology, knowledge itself drops out of epistemology. For our concept of knowledge is inseparably tied to that of justification.' He thus concludes, 'Quine's non-normative, naturalized epistemology has no room for our concept of knowledge' (389). One particular version of epistemic evaluativism especially motivates internalist views of justification. On the deontic theory of justification, a belief is only justified if one cannot be blamed for holding it or obligated to abandon it. But deontic theorists, like Steup, argue that this would make little sense if we could be unaware of what justifies a belief, as externalists allow, since we are not responsible for things of which we are unaware (1998: 311-312). And externalist Alvin Plantinga agrees, even further suggesting that internalism is unmotivated without the deontic view, a position he thoroughly rejects (1993: ch. 1).

Nonetheless, despite epistemic evaluativism's solid footing in contemporary epistemology, the view remains relatively unexplored and little criticized. In particular, seemingly no effort has been made to assess the position in light of traditional debates about the status of normative claims. Against this backdrop, I suggest epistemic evaluativism has some counterintuitive implications. These form the basis 
for two interesting arguments against the position, which are the focus of this paper.

\section{Two conceptual arguments against epistemic evaluativism}

Each of the arguments exploit some odd implications of epistemic evaluativism related to J.L. Mackie's error-theory of value, here understood as the thesis that normative terms are used to attempt to refer to normative properties, but fail to do so, because there are no normative properties. ${ }^{1}$ Now, obviously, the error-theory is just as debatable as its traditional rivals - expressivism and realism - if not more so. However, it is crucial to note that none of the following arguments assume it is correct. Rather, they just make the modest assumption that it is possibly correct — nothing more. ${ }^{2}$ Thus, each argument could be sound, even if the error-theory is false, so long as it is contingently, rather than necessarily, so. In what follows, I will assume Mackie's view is familiar enough for readers to understand and appreciate the issues being raised. With that said, onto the arguments.

At the outset, I would like to briefly present both, with minimal commentary — just enough to initially motivate them. Extended discussion will come later. Here then, is the first:

P1: If epistemic evaluativism is true, then it is contradictory to claim that global epistemic scepticism is false and that the error-theory of value is true.

P2: It is not contradictory to claim that global epistemic scepticism is false and that the error-theory of value is true.

C: Epistemic evaluativism is false.

Clearly, this argument is valid, but is it sound? Consider each premise in turn.

\footnotetext{
${ }^{1}$ An alternative definition would be that evaluative claims are truth-apt, but false. For somewhat technical reasons that I will not delve into here, I think this definition is inadequate. However, as far as my arguments are concerned, either will suffice. For further details, see Mackie 1977: ch. 1.

${ }^{2}$ This assumption is widely accepted in value theory. For arguments on its behalf, more narrowly focused on ethical properties, see Sinnott-Armstrong 2006: ch. 3.
} 
The first premise is trivially true, but worth clarifying. Epistemic evaluativism maintains that knowledge requires the existence of some evaluative condition. So, on this view, any true claim to knowledge implies that some evaluative attributes exist. But the error-theory rejects the existence of any such attributes. Therefore, any affirmation of knowledge and rejection of values is inconsistent on this view. But in my second premise, I deny this. Why?

Let me be concrete about this. Suppose there really are no evaluative attributes. Goodness, badness, justice, injustice, rightness, wrongness, and so on, are all illusory. In other words, Mackie's error-theory is correct — we live in a neutral world. But now carefully consider the following questions. Would such a world altogether preclude knowing? In such a world, every attribution of value would be false. Would this entail that every knowledge claim is false? Could someone really not know that $1+1=2$ just because there are no evaluative properties? I am inclined to think not. Knowledge might not exist in such a world, but this would not be due to the absence of values. If correct, this suffices to prove knowledge does not have an evaluative condition - epistemic claims are neutral. The following example should illustrate these intuitions in an especially vivid way. Suppose you were to ask an error-theorist whether they believe any evaluative properties exist. Naturally, they would answer negatively, but suppose they went further, even claiming to know the errortheory is correct. Now this claim might be false. After all, the errortheory is certainly debatable. But does it really seem self-defeating? Would you accuse your interlocutor of self-refutation? Again, I am inclined to think not. On the face of it, the claim is coherent, if nothing else, but this would not be so, were knowledge even a partly normative concept.

This worry is not isolated. Similar intuitions are revealed by a second argument, which exploits the idea that epistemic evaluativism makes it suspiciously easy to refute the error-theory:

P1: If epistemic evaluativism is true, then every instance of knowledge implies that the error-theory of value is false.

P2: Not every instance of knowledge implies that the error-theory of value is false.

C: $\quad$ Epistemic evaluativism is false. 
Again, the first premise of the argument is trivially true, but why affirm the second? Simple examples reveal its motivation. Suppose that you know a mundane truth, such as $1+1=2$ or that you are conscious at this moment. Do such cases of knowledge, and countless others, really seem to disprove the error-theory? Probably not, but any genuine instance of knowledge would, if knowledge were a normative concept. It is thus fitting to say that epistemic evaluativism makes it rather easy to reject the error-theory. But, ordinarily, it does not seem so easy, at least not to the axiologists devoted to assessing it. I have never heard any of them reject the view on the grounds that they happen to know something (and surely most of them would agree they do happen to know something). This makes epistemic evaluativism moderately suspicious. Nonetheless, even if my conclusion is mistaken, the apparent links between epistemic evaluativism, on the one hand, and value theory, on the other, that these arguments highlight, have gone unnoted. And surely they are important to consider. Let us briefly recapitulate them before moving on.

If knowledge is, indeed, a normative concept, two important implications follow. First, Mackie's error-theory is inconsistent with the existence of knowledge. Technically put, this means the error-theory entails global epistemic scepticism. And any error-theorist that accepts knowledge is thus beset by contradiction. Second, on epistemic evaluativism, any instance of knowledge refutes the error-theory, even if the truth that is known is merely neutral. Moreover, it is worth adding, if epistemic normativity is just a species of a more fundamental evaluative property - a very plausible idea — then any instance of knowledge will establish that property's existence. For instance, if justification is a species of goodness, then genuine knowledge requires the existence of goodness. ${ }^{3}$ Each of these points deserve discussion, for the majority of value theorists, both realists and irrealists of various stripes, have thought that, prima facie, acquiring evaluative knowledge is somehow more problematic and difficult than other kinds of knowledge. But if epistemic evaluativism is correct, this tradition is seriously confused, for knowledge actually requires some evaluative attribute — just the sort of thing there is

\footnotetext{
${ }^{3}$ To be sure, justification might not be a species of goodness, though it is plausible to think it is not a fundamental normative property (more on this later).
} 
supposed to be some special difficulty in knowing — and nothing could be known in any area at all without its existence.

I confess that I find it strange to think that so much follows for value theory simply from the nature and existence of knowledge. But I also find these arguments somewhat compelling. Of course, I do not expect anyone to be convinced merely by this brief presentation. Moreover, I do expect some objections will have already occurred to thoughtful readers. However, I think the obvious worries can be answered - perhaps not decisively, but reasonably enough that both arguments emerge as prima facie challenges to epistemic evaluativism. The remainder of this paper is devoted to further developing these arguments by carefully addressing the basic misgivings, which are liable to be raised about them.

\section{Criticisms and replies}

\subsection{A criticism of scope}

A mild critic of the preceding arguments might grant that they are sound, but only in one sense of 'knowledge.' They might suggest that 'knowledge' has various senses - some neutral, some evaluative and that my arguments hold for the neutral sense of 'knowledge,' but neglect its normative sibling. This would constitute an important qualification regarding the scope of my account. A tough critic might press further though, claiming that the normative sense of 'knowledge' is the important cognitive phenomenon that epistemologists have long aimed to characterize. Therefore, the primary object of epistemological inquiry really does have serious implications for value theory. What to make of this response?

The mild critic might be onto something here; acknowledging the ambiguity of 'knowledge' could explain why people might have different intuitions regarding my arguments, something we should not be slow to consider, though space will not allow me to do so here. The tough critic, on the other hand, is committed to an implausibly strong view, and it is important to clarify exactly why. Roughly put, I think they risk trivializing epistemology as a rather narrow field and scepticism as a surprisingly innocuous view. Neither point might be obvious initially, but they can be reasonably elaborated.

For the sake of argument, suppose that the error-theory and epistemic evaluativism are both true. Under these circumstances, no one 
knows anything. However, suppose that people are still capable of acquiring beliefs with the following neutral attribute, namely, that even if the object of belief is a contingent truth, the judgment is necessarily correct; in other words, assume that we could still achieve infallibility. Such judgments, it must be stressed, do not seem to be inherently evaluative; although we prize the ideal of infallibility, it is not clear that it is actually a normative concept. But crucially then, it is hard to see how acquiring such a belief would fail to satisfy even the very highest cognitive desires of most people. In this scenario, epistemology would be an inquiry into a phenomenon that most people would not particularly care about, given that they could still acquire other kinds of true beliefs, the infallible variety being a rather exalted case. Steadfastly maintaining that my arguments merely target some neutral and unimportant sense of 'knowledge' of little interest to philosophers thus seems to trivialize epistemology as a rather arcane field. From this perspective, epistemology could well be abandoned for a field that is exactly the same, minus the apparently normative properties of beliefs that preoccupy epistemic evaluativists. Look at the problem from another angle.

Consider the case of two hypothetical epistemologists, both of whom are attracted to broadly reliabilist views and take justification to be a necessary condition for knowledge. However, they subtly differ on the nature of justification. One, an epistemic evaluativist, thinks that justification is inherently normative and that acquiring beliefs via reliable processes is merely a criterion for it. The other, an epistemic neutralist, instead thinks that justification simply is the property of stemming from reliable belief-forming processes. Now suppose for the sake of argument that the epistemic evaluativist is right; justification is normative, a necessary condition for knowledge, and reliability is just a criterion for it. And so, contra the sentiments of our epistemic neutralist, a true belief formed via reliable processes does not actually constitute knowledge, unless the evaluative property of justification exists. At this point, the issue I would press is that, with respect to our desires, the subtle difference between these two phenomena - true beliefs acquired via reliable processes vs. justified true beliefs where belief acquisition via reliable processes is a criterion for justification - is small indeed. Even if we only label the former knowledge, as our epistemic evaluativist would have it, I doubt many would value it over the latter. So, even if the tough critic is right in claiming that epistemology is ultimately just concerned 
with some allegedly normative sense of 'knowledge,' I say, so much the worse for epistemology. The discipline is needlessly focused on a property that is seemingly irrelevant to our intellectual goals and desires. And it is on the basis of the latter, I presume, that epistemologists would claim their discipline is widely important, rather than a narrow specialized interest. Therefore, if the tough critic's objection succeeds, I propose it only does so at the cost of trivializing epistemology as a far less important field than it is usually taken to be. Nonetheless, I do take epistemology to be a very important discipline, and so I think it is mistake to claim that it is primarily concerned with an esoteric normative concept, one I imagine few have in mind when pursuing even their very highest cognitive aspirations. ${ }^{4}$ In addition, the tough critic's stance also trivializes some traditional epistemological positions.

Scepticism, for those who take it seriously, is a dismal prospect, to put it mildly. Indeed, worries about its possibility have been the driving force behind much epistemological reflection. However, on the strong critic's position, scepticism becomes rather innocuous, as the following scenario demonstrates. Suppose again, that we really are capable of achieving infallible true beliefs, a purely neutral phenomenon. But, technically speaking, no one truly knows anything, because there are no evaluative attributes, one of which is a necessary condition for knowledge. Granted, people would probably be disappointed by the absence of evaluative attributes, but would they actually care about global ignorance obtaining in this scenario? That seems doubtful. Or suppose someone claims that you do not, in fact, know something you care very deeply about knowing. Trusting the person, I suspect this would be very upsetting. But would it be upsetting if they claimed that you failed to know it, merely on the technicality that knowledge requires justification, a normative property that does not exist, while fully granting that your belief has any number of neutral properties, like infallibility, reliability, coherence, and the

\footnotetext{
${ }^{4}$ It is important not to be misled by my choice of a reliabilist example here. The same considerations hold for competing views of justification. For instance, I doubt that many would desire justified true beliefs, where coherence is simply a criterion for justification, more than coherent true beliefs. And I take this point to general; epistemic evaluativists gain little or nothing by requiring justification as something above and beyond whatever neutral property they currently just offer as a criterion for justification.
} 
like? I doubt anyone would be very moved, if at all, by the prospect of ignorance in these scenarios. But scepticism, when taken seriously, is a very moving prospect for most people, which spells trouble for this sort of view.

\subsection{Criticisms of the first premises}

A more serious objection one might raise is that I have, in some crucial way, mischaracterized the position of epistemologists who claim that knowledge is a normative concept. Perhaps, one might think, I have been too quick to draw a link between claims about epistemic normativity and the traditional theses about value that are routinely discussed in ethics and aesthetics. In short, some will worry that the first premises of both arguments are false and that the alleged normativity of knowledge is simply irrelevant to the error-theory. This is a genuine concern, because the sorts of claims at issue are largely left unclarified; most simply state that justification is a normative notion and move on. So, we need to carefully consider the matter.

At the outset, however, suppose for the sake of argument that the position I am attacking is held far less than it appears and that very few epistemologists are ultimately committed to the view that my arguments target. Under these circumstances, my criticisms have limited scope, but still serve an important function. Surely by this point, epistemic evaluativists must explicate their claims of epistemic normativity. Assuming they are otherwise plausible, here my arguments at least demonstrate what sort of view ought to be avoided in doing so. This is some progress. However, before settling on this modest assessment, we need to ask how credible the charge really is. Can most epistemic evaluativists simply skirt the issues I am raising? Everything depends on what is meant by the claims under issue. Under the circumstances, the best way to approach this is to consider what innocuous things might plausibly be meant in this context. Two suggestions are especially worth considering, though I conclude they are wanting in various respects.

Consider again the claim that justification is normative. One thing that epistemologists could mean here is simply that justification has instrumental value. More specifically, perhaps it is just another way of saying that justification is an effective means of acquiring true beliefs. Clearly, my arguments have no force against this sort of claim, nor are they intended to; instrumental value is uncontroversial and not 
the sort of thing that concerns error-theorists, or any one else, for that matter. But is it reasonable to think this is all that epistemologists have in mind when claiming that justification is an evaluative concept?

In specific cases, this seems unlikely. For example, Goldman says, 'the term 'justified,' I presume, is an evaluative term, a term of appraisal,' and that 'any correct definition or synonym of it would also feature evaluative terms' (1979: 1). Since mere claims of instrumental value can be translated into neutral terms, Goldman, at least, is probably not just making this claim. However, not everyone is so explicit. Is there any other reason to doubt that this is the claim that is usually intended? One compelling reason is simply that the claim that justification is normative would then seem rather odd or misleading. For all sorts of things have instrumental value, but we do not single them out as 'normative' or 'evaluative.' For instance, garbage bags surely have instrumental value, but it would sound odd to thereby claim that the concept of a garbage bag is normative, as so many epistemologists claim of justification. Indeed, since nearly everything possesses some sort of instrumental value, it would appear that every concept would be normative on this view, which clearly stretches the use of 'normative' to unprecedented bounds. This leads me to suspect epistemologists often intend to convey something more than just that justification has instrumental value. Despite all that, I would not be too surprised if some epistemologists meant nothing more than this. They are not the target of my criticisms, but I also doubt they constitute a clear majority of epistemic evaluativists.

Another charitable reading of epistemic evaluativism is a good deal subtler. To approach it, first consider the expressivist theory of normative discourse. Roughly, on this view, normative terms are not meant to refer to normative properties. Rather, they are just used to express attitudes of approval and disapproval. To claim that honesty is good, on expressivism, is not to attempt to ascribe some property to honesty, but just to express a positive attitude toward it. Analogously, an expressivist that took justification to be a pure normative term would understand the claim that some particular belief is justified, not as an attempt to ascribe a property to the belief, but just to express approval of it. This is an extreme position, one I doubt any 
epistemic evaluativist is likely to embrace, ${ }^{5}$ since virtually every epistemologist takes justification to be a property necessary to convert true beliefs into knowledge. However, there is a similar view one might think some epistemic evaluativists have in mind. To understand it, consider now how expressivists view concepts that are partially normative. Murder is commonly taken to be one such concept. On expressivism, in claiming that Smith murdered Jones, one is making the neutral claim that Smith killed Jones, but there is an evaluative element to this claim as well. To account for it, an expressivist will merely claim that in addition to stating that Smith killed Jones, one is also expressing disapproval of it. Along the same lines then, one might think that to claim some particular belief is justified is to ascribe a neutral property to it - reliability, coherence, whatever view happens to be correct - but also to express approval of it. At first glance, this claim seems unobjectionable. And one might think that if this is all epistemic evaluativists have in mind, their view is uncontroversial and irrelevant to the error-theory. However, there are multiple problems with this proposal. To see these, we need to consider two different readings of it.

On the one hand, one might think that epistemic evaluativists are simply using terms like 'normative,' 'evaluative,' and the like, in this special stipulative sense. In other words, stating that knowledge claims are normative might simply be shorthand for saying that they express various attitudes of approval and disapproval. This would be misleading, but otherwise unobjectionable - if one wants to use 'normative' this way, so be it. However, this reading also neglects a number of epistemic evaluativists. To see why, recall that epistemologists embrace epistemic evaluativism in different ways. Some do so, simply because they claim that justification is normative. And since 'normative' is something of a term of art, one can reasonably wonder if a good deal of them mean something very specific by it. Other epistemologists, however, commit to the view in a much bolder fashion. Recall here some of the examples viewed earlier - Ayer's contention that knowledge requires the right to be sure, Zagzebski's definition of knowledge as good true belief, Steup's claim that justifi-

\footnotetext{
${ }^{5}$ Gibbard (1990) might be one exception, since he adopts an expressivist analysis of 'rationality'. It is also interesting to note here that some epistemic evaluativists (e.g., Ayer 1956; Blackburn 1996: 87) champion expressivist views of evaluative discourse, but fail to connect the two.
} 
cation is a deontic notion. These accounts are robustly normative in a rather straightforward way. So, for these views, the issues I am raising are unavoidable. Presently, we can only speculate whether other epistemic evaluativists might clarify their view precisely this way, though hopefully the preceding offers them ample motivation to do so, if it is, in fact, their position.

On the other hand, one might think that epistemic evaluativists would offer this view as a substantive thesis about epistemic normativity, rather than as a mere stipulation. In other words, perhaps they would claim that knowledge is indeed normative and that, on their theory, this just amounts to the linguistic fact that people use epistemic terms to express attitudes of approval and disapproval. Needless to say, such a view would require serious argumentation, though perhaps it could be provided by drawing upon the extensive resources of the expressivist tradition in ethics and aesthetics. Most importantly though, even if this view were ultimately defensible, it would fail to impact my arguments. For, in effect, this proposal would just amount to a rejection of the error-theory on the grounds that it is mistaken in taking uses of normative term as attempts to refer to normative properties. However, this fails to affect my premises, since neither assumes that the error-theory is true, but only that it is possibly true. It still remains that if knowledge were a normative concept, it would be inconsistent to hold that normative terms are meant to refer to normative properties, there are no normative properties, and that some knowledge claims are true. Likewise, it still remains that if knowledge were a normative concept, any true knowledge claim would refute the view that normative terms attempt to refer to normative properties and that there are no normative properties. As regards my arguments then, this objection simply misses the point.

\subsection{Criticisms of the second premises}

A persistent critic might grant the preceding points, but still deny the second premises of my arguments. They will urge that once we delve further, it is not so strange to think that the error-theory entails scepticism or that any true knowledge claim disproves it. And, in any case, it will be said, we simply have no choice but to accept these implications, since knowledge clearly requires justification, a normative notion. How might this reply go? 
Initially, a critic might press that epistemic evaluativism is only committed to the existence of just one kind of normative property, namely, epistemic justification. ${ }^{6}$ And so, while it is strictly speaking true that rejecting scepticism requires rejecting a global error-theory of value, it does not require rejecting an ethical or aesthetic errortheory. They will conclude then, that my account is misleading, because it unfairly exploits the intuitions that we have regarding the link between knowledge claims and error-theories of other sorts of value. This is a reasonable suggestion, but it does face an immediate problem, which can be spelled out as a dilemma.

Either justification is a fundamental normative property or it is just a species of another normative property. Ceteris paribus, economy suggests understanding the Epistemically Justified as just a particular species of some other evaluative property — one we already see as fundamental — rather than setting it alongside the Right and the Good, as it were. But, if justification is just a species of some other normative property, what plausible candidate could there be aside from goodness or rightness? Seemingly none, but the error-theory obviously does concern these properties. Thus, epistemic evaluativists cannot soften a rejection of the second premises by claiming that knowledge only commits us to just one isolated normative property — justification.

Despite this, a critic might say, justification is still a necessary condition for knowledge and it is intuitively obviously that it is normative. Thus, we simply have no choice, but to accept epistemic evaluativism, and its various consequences. Of course, there are large issues simmering beneath this suggestion, which I cannot adequately address here. However, I would like to briefly offer a challenge to it, which I hope further clarifies the issue, even though it cannot be expected to swiftly resolve it. Consider the following scenario. Suppose that you believe a contingent truth and that your belief has the neutral property that it cannot be mistaken. In other words, you have an infallible true belief. Would this count as knowledge? To my mind, and I hope to others, if absolutely any doxastic state is to count as propositional knowledge, this surely would. ${ }^{7}$ And I think this is so, even were we

\footnotetext{
${ }^{6}$ This, of course, neglects bolder epistemic evaluativists. But set that aside and consider this response on behalf of other proponents of the view.

${ }^{7}$ Naturally, some might still require another condition be met, such as access to the source of one's belief, a point for which I thank an anonymous referee of
} 
to reject the existence of all normative properties, including justification. Still, a counterexample without a positive alternative is liable to be disappointing. And an epistemic evaluativist may claim that the epistemological tradition offers little assistance here; few, if any, epistemologists claim that justification is a neutral concept or offer accounts of knowledge that do not require it. Developing either strategy would far exceed my aim here, which is merely to motivate considering them. Nevertheless, let me conclude by very briefly indicating to what extent I think the tradition can accommodate either strategy.

\section{Conclusion}

On the face of it, it sounds rather absurd to suggest that 'justification' is a neutral term, for, in ordinary discourse, the term is clearly evaluative. However, it is easy to pass over the fact that within epistemology, 'justification' is still a term of art, appropriated from ordinary contexts. And it is not obvious that all epistemologists mean to import the normative elements of that term into their philosophical reflections. For some, it would not be too surprising if, in the first instance, 'justification' were little more than a placeholder for whatever property is necessary to prevent lucky guesses from counting as knowledge. On such a view, this choice of terminology would not be meant to convey anything normative, as it does in ordinary usage. It could thus accommodate my conclusions and perhaps some epistemologists think something like this. However, 'justification' seems patently normative, unless taken in this stipulative and rather uninformative sense. This makes the alternate strategy — denying that justification is a necessary condition for knowledge - a more appealing option. Nevertheless, the necessity of justification remains a near unanimous conviction among epistemologists, despite the interminable disputes regarding its proper analysis. An interesting exception, however, are the pioneers of externalism. Originally, externalists, such as D.M. Armstrong (1973), offered their views as rivals to the suggestion that justification is necessary to convert true beliefs into knowledge. Admittedly, this tradition has flagged considerably since

reminding me. Nevertheless, the main point is that I think virtually everyone could construct some such example — one they would feel little hesitation in calling knowledge — without requiring any normative conditions to be satisfied. 
the publication of Goldman's seminal essay, 'What is Justified True Belief?,' which recast externalism as a distinctive account of justification. However, this earlier program is clearly consistent with the account presented here and, I suggest, constitutes one promising avenue for the development of a neutralized epistemology.

$$
\begin{array}{r}
\text { Brian Laetz } \\
\text { Department of Philosophy } \\
\text { University of British Columbia } \\
\text { Vancouver, BC V6T 1Z1, Canada } \\
\text { blaetz@interchange.ubc.ca }
\end{array}
$$

References

Armstrong, D.M. 1973. Belief, Truth, and Knowledge. Cambridge: Cambridge University Press.

Ayer, A.J. 1946. Language, Truth, and Logic. London: Gollancz.

Ayer, A.J. 1956. The Problem of Knowledge. London: Macmillan.

Blackburn, Simon. 1996. Securing the Nots: Moral Epistemology for the Quasi-Realist. In Moral Knowledge?: New Readings in Moral Epistemology, edited by W. Sinnott-Armstrong and M. Timmons. Oxford: Oxford University Press.

Blackburn, Simon. 1998. Ruling Passions: A Theory of Practical Reasoning. Oxford: Clarendon Press.

Gibbard, Allan. 1990. Wise Choices, Apt Feelings: A Theory of Normative Judgment. Cambridge, MA: Harvard University Press.

Goldman, Alvin. 1979. What is justified belief? In Justification and Knowledge: New Studies in Epistemology, edited by G. Pappas. Dordrecht: Reidel.

Goldman, Alvin. 2006. Simulating Minds: The Philosophy, Psychology, and Neuroscience of Mindreading. Oxford: Oxford University Press.

Kim, Jaegwon. 1988. What is 'Naturalized Epistemology'? Philosophical Perspectives 2: 381-406.

Mackie, J.L. 1977. Ethics: Inventing Right and Wrong. Harmondsworth: Penguin Books.

Moser, P., Mulder, D. and Trout, J.D. 1998. The Theory of Knowledge: A Thematic Introduction. New York: Oxford University Press.

Plantinga, Alvin. 1993. Warrant: The Current Debate. Oxford: Clarendon Press.

Pollock, John and Cruz, Joseph. 1999. Contemporary Theories of Knowledge. Totowa: Rowman and Littlefield.

Quine, W.V.O. 1969. Epistemology Naturalized. In Ontological Relativity and Other Essays. New York: Columbia University Press. 
Sinnott-Armstrong, Walter. 2006. Moral Skepticisms. New York: Oxford University Press.

Steup, Matthias. 1996. An Introduction to Contemporary Epistemology. Upper Saddle River: Prentice Hall.

Steup, Matthias. 1998. A Defense of Internalism. In The Theory of Knowledge, edited by L. Pojman. Belmont: Wadsworth.

Zagzebski, Linda. 1999. What is Knowledge? In The Blackwell Guide to Epistemology, edited by J. Greco and E. Sosa. Oxford: Blackwell. 